\title{
A Prospective Study to Assess the Effectiveness of Extracorporeal Shock Wave Lithotripsy Versus Ureteroscopy for Proximal Ureteral Calculi Between Sizes 5 to $10 \mathrm{~mm}$
}

\author{
Bikash Bahadur Rayamajhi ${ }^{1}$, Anjan Khadka ${ }^{2}$ and Narayan Thapa ${ }^{1}$
}

${ }^{1}$ Department of Surgery, Nepalese Army Institute of Health Sciences, Shree Birendra Hospital, Chhauni, Kathmandu, Nepal

${ }^{2}$ Department of Pharmacology, Nepalese Army Institute of Health Sciences, Sanobharyang, Kathmandu, Nepal

\begin{abstract}
Introduction: There are various international guidelines for the surgical treatment of upper ureteral calculi. For upper ureteral stone of less than $10 \mathrm{~mm}$ size, ESWL and URS are regarded as first line treatment. However, there is lack of national guidelines for appropriate surgical options for such stone in our settings.

Methods: The study was prospective comparative type involving 100 patients who were divided into ESWL and URS groups comprising 50 patients in each. ESWL and URS were performed after confirmation of stone size with ultrasonography and non-contrast enhanced computed tomography. All patients underwent X-ray KUB at one week and six weeks post procedure for confirmation of stone clearance. Those with residual calculi of size $<5 \mathrm{~mm}$ were considered stone free. Statistical analysis was done using Graph pad prism version 6 .

Results: The mean age of patients in ESWL and URS groups were $41.28 \pm 15.3$ years and $42.84 \pm 16.1$ years respectively. The male to female ratio was higher in ESWL group. The mean size of the stone pre ESWL was $8.58 \mathrm{~mm}$ and pre URS was $8.44 \mathrm{~mm}$. The percentage of stone clearance at one week and six weeks for ESWL was $56 \%$ and $90 \%$ respectively whereas for URS, it was more than $90 \%$ at both one week and six weeks. The complications were higher with URS (20\%) than ESWL (8\%).
\end{abstract}

Conclusions: The ESWL and URS are equally effective in stone clearance. The duration is longer with ESWL and the complications were more in URS group.

Key words: Lithotripsy; Stents; Ureteral Calculi; Ureteroscopy

Correspondence: Bikash Bahadur Rayamajhi, Department of Surgery, Shree Birendra Hospital, Nepalese Army Institute of Health Sciences, Sanobharyang, Kathmandu, Nepal. E-mail: drbikashrayamajhi@gmail.com

DOI: http://dx.doi.org/10.3126/mjsbh.v19i2.27535

Submitted on: $2020-02-03$

Accepted on: 2020-04-22

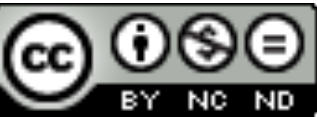

This work is licensed under creative common license:

http://creativecommons.org/licenses/by-nc-nd/4.0/ @ MJSBH 2020 


\section{INTRODUCTION}

Ureteral calculi are one of the causes of morbidity of urinary tract system and when treatments are required, it should be high stone free with low complication. The life time risk of urolithiasis is estimated at $10 \%$ to $15 \%$, with the probability of having a stone varying according to age, gender, race, and geographic location. ${ }^{1}$ The rate of spontaneous stone passage correlates with stone size and stone location. The rate of spontaneous passage of stone of size less than $4 \mathrm{~mm}$ is approximately $76 \%$ in general whereas for proximal ureteral stone it is approximately $48 \% .^{2}$ There are various surgical treatment options like open ureterolithotomy, extracorporeal shock wave lithotripsy (ESWL) and ureteroscopy (URS) for ureteral stone based on stone location, size, patient's co-morbidities and preference. Ureteroscopy is a minimally invasive procedure performed under direct-vision using pneumatic, ultrasonic or laser lithotripter for stone fragmentation with success rate of approximately 95\% whereas ESWL is a non-invasive procedure performed on outpatient basis using low amplitude, high frequency shock waves with predictable success rate of $80-90 \%$ and fewer complications. ${ }^{3}$

Among the various guidelines for surgical treatment of upper ureteral stone, guidelines of the American Urological Association (AUA) and the European Association of Urology (EAU) differ on the most appropriate treatment option. For upper ureteral stone of $<10 \mathrm{~mm}$ size, EUA recommends ESWL as first line treatment whereas AUA recommends URS as first line and ESWL as second line therapy. ${ }^{4}$ Ambiguities and discrepancies between the different guidelines and failure to develop our own national guidelines are the challenges for surgeons in choosing the most appropriate procedure. Hence, to fulfil the unmet need on most appropriate treatment options for upper ureteral stone, this study was done to assess the effectiveness of ESWL versus URS with pneumatic lithotripsy in the management of upper ureteral stone between $5 \mathrm{~mm}$ to $10 \mathrm{~mm}$ in size.

\section{METHODS}

This was a prospective observational comparative study involving 100 patients with upper ureteral calculus of size between $5 \mathrm{~mm}$ to $10 \mathrm{~mm}$ in diameter, conducted at department of surgery of tertiary care hospital of Central Nepal from first
December 2018 to $30^{\text {th }}$ November 2019. Approval of the Institutional Ethics Committee along with patient consent was taken before commencement of the study. We define upper ureteral stone as those stone found above the upper border of sacrum. Patient with uncomplicated solitary upper ureteral stone between $5 \mathrm{~mm}$ to $10 \mathrm{~mm}$ in size was included in the study however, ureteral stone with Hounsfield unit less than 1000 was only included in the ESWL group. Patient with hemostatic disorders, pregnancy, calcified aortic aneurysm were excluded from the study. All patient underwent preoperative abdominal ultrasonography (USG), non-contrast enhanced computed tomography (NCCT) scan of abdomen, routine blood test, coagulation profile and urinalysis. After discussing the available therapeutic options, the patient were divided into two groups viz. ESWL group and URS group comprising 50 patients per group.

ESWL was performed after 12 hours of fasting and bowel preparation with two tablets of dulcolax taken at bedtime one day before the procedure. ESWL was performed by an Electro Magnetic Lithotripter (Initia Ltd, Israel) under analgesia. A maximum of 3000 shocks per session at a cycle of 80 per minute was given with gradual increment in intensity up to $30-40 \mathrm{kV}$. Post procedure all patients underwent X-ray KUB for confirmation of clearance of stone.

URS was performed under spinal anesthesia after eight hours of fasting and X-ray KUB taken on the morning of the procedure. Ureteroscopy was done with an 8/9.8 Fr, $55 \mathrm{~cm}$ Karl $\mathrm{Storz}^{\mathrm{TM}}$ semirigid ureteroscope. Stone was fragmented using pneumatic Swiss Lithocast with $0.8 \mathrm{~mm}$ probe under low pressure stream of normal saline. Patient with suspected ureteral injury, proximal stone migration or retained stone of size $\geq 5 \mathrm{~mm}$ were DJ stented. All patients were discharged on first postoperative day after confirmation of stone clearance and position of DJ stent with X-ray KUB. In both the groups, patient were prescribed with tablet tamsulosin $0.4 \mathrm{mg}$ taken at bed time for six weeks, tablet levofloxacin $750 \mathrm{mg}$ once daily for five days and tablet diclofenac $50 \mathrm{mg}$ as when required for pain.

Both ESWL and URS group patients were informed about the possible complications and advised for follow up in urology OPD at one week and six weeks with X-ray KUB and USG KUB taken on the same day. Those with residual calculi 
of size $<5 \mathrm{~mm}$ were considered stone free. Data was entered in the MS-Excel and expressed in mean \pm standard deviation (SD). Graph pad prism version 6 was used for statistical analysis. ANOVA test was used for comparison of more than two variables whereas t-test was used to compare between two groups. A ' $p$ ' value $<0.05$ was considered statistically significant.

\section{RESULTS}

The mean age of patients in ESWL group was $41.28 \pm 15.3$ years and URS group was $42.84 \pm$ 16.1 years. The total number of males and females involved in the study were 61 and 39 respectively. The numbers of patients in different age groups among two groups are shown in table 1 . The male to female ratio in ESWL and URS groups were 1.8:1 and 1.4:1 respectively.

The mean size of the stone before procedure for ESWL group was $8.58 \mathrm{~mm}$ and for the URS group was $8.44 \mathrm{~mm}$. The differences between the mean stone size at admission (pre-procedure), at one week and at six weeks (post procedure) among both the groups are shown in table 2 .

The percentage of stone clearance at one week and at six weeks of follow up for ESWL and URS group is shown in figure 1. It was found that there exist significant differences in the immediate clearance rate $(p<0.005)$, however there is no significant differences at six weeks follow up ( $p>$ 0.005). All five failure patients with residual stone of size $\geq 5 \mathrm{~mm}$ were given second session of ESWL and reassessed at one week and six weeks respectively as before. Among five patients with

Table 1. Responses to the TBD questionnaires

\begin{tabular}{|l|l|r|r|r|r|}
\hline \multicolumn{2}{|c|}{$\begin{array}{c}\text { Age } \\
\text { group in } \\
\text { years }\end{array}$} & \multicolumn{2}{c|}{ ESWL } & \multicolumn{2}{c|}{ URS } \\
\hline 1 & $11-20$ & 2 & 1 & 2 & 0 \\
\hline 2 & $21-30$ & 8 & 5 & 7 & 6 \\
\hline 3 & $31-40$ & 7 & 5 & 6 & 7 \\
4 & $41-50$ & 2 & 3 & 2 & 2 \\
\hline 5 & $51-60$ & 9 & 2 & 6 & 1 \\
6 & $61-70$ & 3 & 2 & 5 & 5 \\
7 & $71-80$ & 1 & 0 & 1 & 0 \\
\hline Total & & 32 & 18 & 29 & 21 \\
\hline
\end{tabular}

second session of ESWL, stone clearance was seen in four patients however, remaining one patient required URS for stone clearance. Similarly, four post URS patient with residual stone of size $\geq 5$ $\mathrm{mm}$ required second setting of URS, of which stone clearance was seen in three patients whereas one patient had proximal stone migration which required percutaneous nephrolithotomy (PCNL).

Out of 50 patients in each group, the number of complications observed in ESWL group was four $(8 \%)$ and URS group was $10(20 \%)$. In the ESWL group, three patients had steinstrasse at one week follow up which required DJ stenting and one patient had transient hematuria. Similarly, in URS group, transient hematuria was seen in six patients, ureteral injury was seen in three patients and one patient had stone migration which was immediately converted to PCNL. Among 50 patients in URS group, 22 required DJ stenting which was removed on six weeks post operatively.

\section{DISCUSSION}

This study included 100 patients with 5 to $10 \mathrm{~mm}$ upper ureteral stone with the mean age similar in both the groups. Our findings were similar to the study by Iqbal $\mathrm{N}$ et al who reported mean age of $39.21 \pm 13.36$ years in ESWL and $43.13 \pm 13.65$ years in URS group. ${ }^{3}$ The male to female ratio in ESWL and URS group was 1.8:1 and 1.4:1 which were similar to the study done by Tiloklurs $\mathrm{C}$ et al. who reported male to female ratio of 2.1:1 for ESWL and 1.34:1 for URS group. ${ }^{5}$ Our study showed maximum number of patients from 21 to 30 age groups in ESWL and 21 to 30 and 31 to 40 age groups in URS group.

The mean size of stone before the procedure was slightly larger in ESWL group ( $8.58 \mathrm{~mm}$ ) than URS group $(8.44 \mathrm{~mm})$. Nikoobakht MR et al. reported the mean stone size of 8 and $9 \mathrm{~mm}$ for ESWL group and URS group respectively. ${ }^{6}$ The average size of stone in our study was smaller as compared to the study conducted by Bucci $\mathrm{S}$ et al. which

Table 2. Size of stone pre and post ESWL and URS

\begin{tabular}{|c|c|c|c|c|c|}
\hline $\begin{array}{l}\mathbf{S} \\
\mathbf{N}\end{array}$ & Procedure & $\begin{array}{c}\text { At } \\
\text { admission }\end{array}$ & $\begin{array}{l}\text { At } 1 \\
\text { week }\end{array}$ & $\begin{array}{c}\text { At } 6 \\
\text { weeks }\end{array}$ & $\begin{array}{c}\mathrm{p} \\
\text { value }\end{array}$ \\
\hline 1 & ESWL & $\begin{array}{l}8.58 \pm \\
0.96\end{array}$ & $\begin{array}{l}4.0 \pm \\
1.75\end{array}$ & $\begin{array}{l}1.18 \pm \\
1.73\end{array}$ & $\begin{array}{c}< \\
0.005\end{array}$ \\
\hline 2 & URS & $\begin{array}{l}8.44 \pm \\
0.96\end{array}$ & $\begin{array}{l}1.36 \pm \\
1.63\end{array}$ & $\begin{array}{l}0.68 \pm \\
1.56\end{array}$ & $\begin{array}{c}< \\
0.005\end{array}$ \\
\hline
\end{tabular}




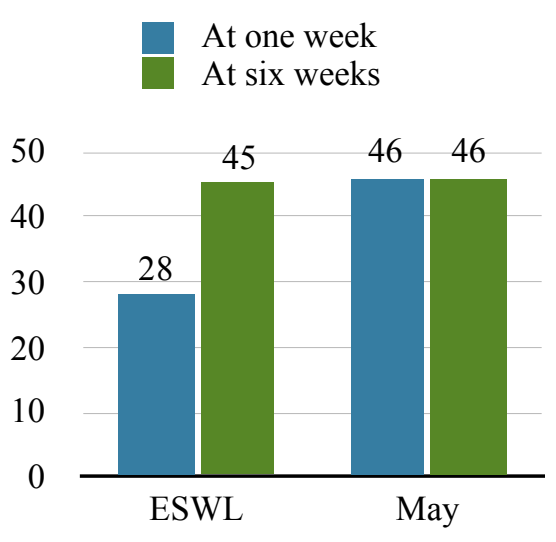

Table 3. Clearance rate of stone

showed $9.8 \mathrm{~mm}$ and Jeon $\mathrm{SS}$ et al. showed 10 mm. ${ }^{7,8}$ Both ESWL and URS are accepted treatment modalities of treatment for upper ureteral calculus less than $10 \mathrm{~mm}$, however regarding the first line therapy different guidelines differ. ${ }^{4}$ The AUA guidelines differ with the guidelines of EUA, Singapore Urological Association, German Society for Urology, French Association for Urology which recommends ESWL as first line therapy. ${ }^{4,9}$ The percentage of stone clearance in our study at one week and six weeks of follow up for ESWL group was $56 \%$ and $90 \%$ whereas for URS group more than $90 \%$ post procedure. Though the immediate stone clearance rate at one week follow up of ESWL group was low, the clearance rate for both ESWL and URS group was about $90 \%$ almost similar to the study done by Tripathi SP et al. ${ }^{10}$ However, the study done by Shaikh AA et al. showed better stone clearance rate with ESWL than URS. ${ }^{11}$ The stone clearance rate in our study following single session of ESWL was found to be higher as compared to other studies which might be due to inclusion of 5 to $10 \mathrm{~mm}$ proximal ureteral stone with density $<1000$ Hounsfield Unit which is similar to the cutoff point taken by Ouzaid et al. ${ }^{12}$ Study done by Preminger GM et al. reported stone clearance rate of $90 \%$ and $80 \%$ for ESWL and URS group respectively. There is no difference in stone clearance rate with ESWL and URS after six weeks which is coherent to the findings of Tripathi SP et al. which showed stone clearance rate for both groups to be $90 \%$ at three months follow up. ${ }^{10}$ The conversion rate of ESWL to URS was low. Among five patients from ESWL group with residual stone, $80 \%$ were successfully treated using second session of ESWL where as $20 \%$ case required URS for complete clearance. ESWL failure may be because of stone impaction or migration. Similarly, among four patients from URS group, 75\% were successfully treated with second session of URS and $25 \%$ case required PCNL because of stone migration. The re-treatment or auxillary treatment rates between ESWL and URS were 20\% and 25\% with ESWL and URS group which are similar to the study by Geraghty RM et al. ${ }^{13}$

Both ESWL and URS treatment have been shown to be safe and effective but requires expensive equipments and urological expertise. The complication rate was higher with URS in comparison to ESWL because URS is more invasive, requiring anaesthesia. There was no major complications noted in both the groups, however $8 \%$ patients in the ESWL had complication in the form of steinstrasse and haematuria. Similarly, 20\% patients from URS group had minor complications in the form of transient haematuria, ureteral injury and stone migration. The complication rate in our study was higher than the findings of Ghalayini IF et al who reported a complication rate of $3.3 \%$ and $8.3 \%$ for the ESWL and URS groups, respectively. ${ }^{14}$ Though avoiding stents lowers costs and gives fewer irritative symptoms, 22 out of 50 patients required DJ stenting for six weeks post operatively. ${ }^{15}$

\section{CONCLUSIONS}

The treatment of ureteral calculi has undergone a significant evolution from open uretero-lithotomy and blind stone basket manipulation to lesser invasive modalities like ureteroscopy and extracorporeal shock wave lithotripsy. Though our study found ESWL and URS equally effective in reducing the stone size and need for secondary, and/or adjunctive procedures, the complications were more in URS group. The duration to achieve the stone clearance is longer with ESWL as compared to URS but ESWL is non-invasive and can be performed in OPD with minimal complications. Therefore, ESWL is more beneficial in centres with limited skilled manpower and huge patient load. However, further studies in multiple centres and with large samples are required to standardise the choice of treatment modalities between ESWL and URS.

\section{ACKNOWLEDGEMENT}

Prof Dr Bhairab Kumar Hamal, Shree Birendra Hospital, Chhauni 
To cite this article: Rayamajhi BB, Khadka A, Thapa N. A Prospective Study to assess the effectiveness of extracorporeal shock wave lithotripsy versus ureteroscopy for proximal ureteral calculi between sizes 5 to $10 \mathrm{~mm}$. MJSBH. 2020;19(2):65-9.

\section{REFERENCES}

1. Sorokin I, Mamoulakis C, Miyazawa K, Rodgers A, Talati J, Lotan Y. Epidemiology of stone disease across the world. World J Urol. 2017;35(9):1301-20. DOI: 10.1007/s00345-017-2008-6

2. Jendeberg J, Geijer H, Alshamari M, Cierzniak B, Lidén M. Size matters: the width and location of a ureteral stone accurately predict the chance of spontaneous passage. Eur Radiol. 2017;27(11):4775-85. DOI: 10.1007/ s00330-017-4852-6

3. Iqbal N, Malik Y, Nadeem U, Khalid M, Pirzada A, Majeed M, et al. Comparison of ureteroscopic pneumatic lithotripsy and extracorporeal shock wave lithotripsy for the management of proximal ureteral stones: A single center experience. Turk J Urol. 2018;44(3):221. DOI: 10.5152/tud.2018.41848

4. Zumstein V, Betschart P, Abt D, Schmid HP, Panje CM, Putora PM. Surgical management of urolithiasis: A systematic analysis of available guidelines. BMC urology. 2018;18(1):2-8. DOI: 10.1186/s12894-018-0332-9

5. Tiloklurs C, Taweemonkongsap T, Amornvesukit T, Phinthusophon K, Nualyong C, Chotikawanich E. Comparison of Successful Treatment between Ureteroscopic Lithotripsy and Extracorporeal Shock Wave Lithotripsy for Proximal Ureteric Calculi. J Med Assoc Thai. 2017;100(2):150-4.

6. Nikoobakht MR, Emamzadeh A, Abedi AR, Moradi K, Mehrsai A. Transureteral lithotripsy versus extracorporeal shock wave lithotripst in management of upper ureteral calculi. J Urol. 2007;4:207-11. PMID: 18270943

7. Bucci S, Umari P, Rizzo M, Pavan N, Liguori G, Barbone F, et al. Emergency extracorporeal shockwave lithotripsy as opposed to delayed shockwave lithotripsy for the treatment of acute renal colic due to obstructive ureteral stone: a prospective randomized trial. IJUN. 2018 Oct;70(5):526-33.DOI: 10.23736/S0393-2249.18.03084-9

8. Jeon SS, Hyun JH, Lee KS. A comparison of holmium:YAG laser with lithocast lithotripsy in ureteral calculi fragmentation. Int J Urol. 2005;12(6):544-7. DOI: 10.1111/j.1442-2042.2005.01087.x

9. Preminger GM, Tiselius HG, Assimos DG. Guidelines on urolithiasis. J Urol. 2007;178(6):2418-34. DOI: 10.1016/ j.juro.2007.09.107

10. Tripathi SP, Jain DK, Dinesh M, Pathak P. Comparative study of ureteroscopy versus extracorporeal shock wave lithotripsy in management of upper ureteral calculi. IJMHS. 2018;8(8):88-94. DOI: 10.15520/ijmhs.v8i7.2238

11. Shaikh AA, Patujo YH, Shaikh AB, Abbasi B. Comparison of intracorporeal (Pneumatic) versus extracorporeal shockwave lithotripsy (ESWL) in proximal ureteral stone management. PJMHS. 2018;12(1):390-3.

12. Ouzaid I, Al-qahtani S, Dominique S, Hupertan V, Fernandez P, Hermieu JF, et al. A 970 Hounsfield units (HU) threshold of kidney stone density on non-contrast computed tomography (NCCT) improves patients' selection for extracorporeal shockwave lithotripsy (ESWL): evidence from a prospective study. BJU International. 2012;110(11b):438-42. DOI: 10.1111/j.1464-410X.2012.10964.X

13. Geraghty RM, Jones P, Herrmann TR, Aboumarzouk O, Somani BK. Ureteroscopy is more cost effective than shock wave lithotripsy for stone treatment: systematic review and meta-analysis. World J Urol. 2018;36(11): 1783-93. DOI: $10.1007 / \mathrm{s} 00345-018-2320-9$

14. Ghalayini IF, Al-Ghazo MA, Khader YS. Extracorporeal shockwave lithotripsy versus ureteroscopy for distal ureteric calculi: efficacy and patient satisfaction. Int Braz J Urol. 2006;32(6):656-67. DOI: 10.1590/ s1677-55382006000600006

15. Başeskioğlu B, Sofikerim M, Demirtaş A, Yenilmez A, Kaya C, Can C. Is ureteral stenting really necessary after ureteroscopic lithotripsy with balloon dilatation of ureteral orifice? A multi-institutional randomised controlled study. World J Urol. 2011;29(6):731-6. DOI: 10.1007/s00345-011-0697-9 